\title{
Psychosocial Risk Factors of Cancer Diseases: How Specific Are They?
}

\author{
Shulamith Kreitler ${ }^{1}$, Michal M. Kreitler ${ }^{1}$, Frida Barak ${ }^{2}$ \\ ${ }^{1}$ Department of Psychology, Tel Aviv University and Psychooncology Research Center, \\ Sheba Medical Center, Tel Hashomer, Israel \\ ${ }^{2}$ Oncology Department, Barzilai Medical Center, Ashkelon, Israel \\ Email: krit@netvision.net.il
}

Received 2013

\begin{abstract}
The paper presents the psychological correlates of colorectal cancer patients in the framework of the cognitive orientation (CO) theory. According to this cognitive-motivational approach the major factors responsible for disease are a pathogene, background factors and a physiological program implementing the disease processes. Psychological factors form a part of the background factors. They consist of specific cognitive contents forming a motivational disposition, representing four types of beliefs referring to specific contents. The cognitive contents are assessed by a CO questionnaire. Previous studies showed that the CO questionnaire differentiated significantly between colorectal cancer patients and healthy controls in two samples, as well as between both groups and Crohn patients who have potential malignancy. The present study was designed to examine the specificity of the psychological variables characterizing colorectal cancer. The CO questionnaire was administered to male colorectal cancer patients and patients with prostate cancer and male healthy controls, and to female colorectal cancer patients, patients with breast cancer and healthy female controls. In both cases the scores of the CO questionnaire differentiated between the colorectal cancer patients and the two other groups, but there were no differences between the prostate cancer patients or the breast cancer patients and the healthy controls. These findings confirm the hypothesis that the $\mathrm{CO}$ variables of colorectal cancer are disease specific and may be considered as psychological risk factors for colorectal cancer.
\end{abstract}

Keywords: Colorectal Cancer; Personality; Cognitive Orientation; Risk Factors

\section{Introduction}

Search for risk factors of cancer diseases in the Medline file yields 81,380 items (for Dec. 3, 2013), listing variables such as genetics, age, nutrition, obesity, ethnic background, alcohol consumption, lack of physical exercise, or ingestion of specific medications but very few if any refer to psychosocial risk factors. The paucity of scientific interest in psychological risk factors of cancer is not surprising in view of controversial findings in this domain. Some of the findings, such as about the Type C personality type (Temoshok, Heller, Sagebiel et al., 1985) were not reproduced (Amelang, 1997; Fox, 1998; Goodkin, Antoni, Sevin et al., 1993; Lilja, Smith, Malmstroem et al., 1998; Servaes, Vingerhoets, Vreugdenhil et al., 1999), others were shown to result from the disease itself (Kreitler, Kreitler, \& Chaitchik, 1993) and still others were identified as correlates of chronic diseases in general (Denollet, 1998; Sanderman \& Ranchor, 1997).

The major shortcomings of the previous studies were that they used subjects varying in medical and psychosocial characteristics which could seriously affect the results, such as cancer diagnoses, duration of disease, and quality of life; that they mostly did not consider sufficiently relevant medical variables, such as precise diagnosis, stage of disease, or medical risk factors; that the psychological variables selected for the studies were not grounded in a theory that bound them to the disease and sometimes could even be affected by the disease itself, such as depression.
The present study is based on applying to the issue of psychosocial risk factors for cancer diseases the theory of cognitive orientation (CO).

\section{The Cognitive Orientation Theory: The CO Model of Health}

The CO is a comprehensive cognitive-motivational theory of a variety of outputs (Kreitler, 2004; Kreitler \& Kreitler, 1976, 1982). A major version of the theory is the CO model of health, which provides a well-validated and empirically-based approach to the impact of psychological variables on diseaserelevant physiological processes (Kreitler \& Kreitler, 1991a, 1991b, 1996, 1998; Kreitler, 2003). The CO approach to physical diseases is based on the assumption that three major factors are necessary for the occurrence of a disease: the pathogene which is the carrier or instigator of the disease, such as a virus or a microbe; background factors that modulate the vulnerability of the organism to succumb to the pathogene or resist its impact; and a physiological mechanism or procedure that implement the development and occurrence of the disease. The $\mathrm{CO}$ theory focuses on the background factors. These may include intra-organismic variables, such as immunological state, nutritional variables and co-morbidity, as well as extra-organismic variables, such as air pollution, toxins, and environmental danger. According to the CO theory, the background factors include always also psychological factors. This however in no way justifies considering the disease as a psychosomatic for the 
background factors merely modulate the impact of the pathogene on the organism. The major advantage of the CO theory for the study of psychological factors that play a predisposing role in regard to cancer is that it provides a methodology for identifying the adequate variables. Adequacy of the variables means on the level of theory that they are relevant for a particular disease; they constitute theoretically a homogeneous and comprehensive set of factors; and they are not under the conscious or voluntary control of the participant. On the empirical level adequacy of the variables means that they may be empirically validated, i.e., they significantly differentiate between patients and controls and they are amenable for change in a wellcontrolled clinical intervention.

It is a characteristic of background factors that they are disease-specific, so much so that background factors, which may promote disease occurrence for one disease, may act as inhibiting factors for another disease, as in the case of cholesterol in regard to cardiological and malignant diseases. Hence, a construct as 'stress' is too general to do justice to the specificity of the relevant psychosocial background factors.

The CO theory of physical health focuses on identifying and changing the relevant psychological risk factors for diseases.

The main tenet of the theory is that the psychological risk factors of the disease are cognitive contents of a specific kind. The cognitive contents express how the individual conceptualizes or experiences external and internal states and objects. The cognitions are characterized in two respects: formally and in terms of contents. The formal characterization is in terms of four types of beliefs: a) Beliefs about self, which express information about oneself, such as one's habits, actions or feelings (e.g., "I often get angry", "I was born in London”); b) Be- liefs about rules and norms, which express ethical, esthetic, social and other rules and standards (e.g., "One should be assertive”); c) General beliefs, which express information concerning others and the environment (e.g., "The world is a dangerous place"; and d) Beliefs about goals, which express actions or states desired or undesired by the individual (e.g., "I want to be respected by others"). Formally, the beliefs differ in the subject (in beliefs about self and goals the subject is the self, in general beliefs and norms it is non-self) and in the relation between subject and predicate (in beliefs about self and general beliefs it is factual, in norms the desirable, in goals the desired).

The characterization of the cognitions in terms of contents is based on a standard procedure of stepwise meaning probing administered in pretests with subjects, some of whom have the disorder and some who do not (Kreitler \& Kreitler, 1991a). The procedure consists in asking the subjects to express the generally accepted meaning of the disease and related keywords, and then to express successively the personal meanings of the communicated meanings, three times in a row. Thus, schematically, the subject is asked to communicate the common meaning of the disease and then to communicate the meaning of what he or she stated and thus twice more. The resulting meanings on the final level are assessed for similarities by independent judges. The meanings that recur in at least $50 \%$ of the subjects with the disease and no more than in $10 \%$ of those without the disease are accepted as "themes" expressing the contents of the cognitive orientation of the disease. These themes are used for constructing the CO questionnaire of the disease: for each theme four beliefs are phrased, one in each belief type. For example, the beliefs referring to the theme of perfectionism could be the following: "In whatever I do I try to achieve perfection" (belief about self); "If one tries hard enough it is possible to attain perfection” (general belief); "One should never try to achieve perfection” (belief about norm, reversed); "I would like not to try to achieve perfection" (belief about goals, reversed). The CO questionnaire consists of four parts, each devoted to one of the types of beliefs. In each part there are randomly ordered statements to which the subject is requested to respond by checking one of the following response alternatives, scored 1 to 4: "very true", "true", "not true" and "not at all true" (in the case of goal beliefs the alternatives were “want very much”, “want”, “don’t want”, “don’t want at all”). The scores are the means of the responses the subject gave to each set of statements referring to the four belief types. These four scores are the major ones, complemented by scores representing the different themes in the CO questionnaire.

The four diseases belief types referring to the themes specific for a particular disease form a vector representing the motivational disposition for the disease. If all four belief types support the disease (i.e., the scores are high) the chances for the occurrence of the disease $\mathrm{i}$ the presence of a pathogene are increased. The CO model of health has been applied successfully in regard to different diseases, including cancer (Drechsler, Bruner, \& Kreitler, 1987; Kreitler, Levavi, \& Bornstein, 1996; Kreitler \& Kreitler, 1991a; Nurymberg, Kreitler, \& Weissler, 1996).

\section{The CO of Colorectal Cancer}

The present study focuses on the psychological risk factors for colorectal cancer. The $\mathrm{CO}$ of colorectal cancer has been identified and presented in two previous studies. The first study (Figer, Kreitler, Kreitler et al., 2002) focused on identifying and establishing the psychological risk factors for colorectal cancer. The CO questionnaire included beliefs of the four types that referred to 44 themes that had been extracted from interviews conducted with pretest participants (15 colon cancer patients and 15 healthy controls) according to a standard procedure (Kreitler \& Kreitler, 1991a). The final draft of the questionnaire was obtained after the completion of standard psychometric analyses and tests, and included a total of 181 items presented in four parts referring to each of the four types of beliefs. The reliability was satisfactory for each part and for the whole questionnaire.

A factor analysis of the themes in the CO questionnaire yielded the following eight factors: a) attaining peace and quiet in one's environment through restraint and self-regulation; b) fulfilling one's duties and commitments; c) suppressing anger; d) toughness in regard to oneself; e) fighting injustice; f) controlling others; g) avoiding being controlled by others; and h) pleasing others.

The CO questionnaire was administered to 106 patients who had been diagnosed with colorectal cancer and 99 healthy controls. The results showed that the patients and controls differed significantly in the four belief types, and in seven of the eight factors. In all variables, the patients scored higher than the controls, as predicted by the CO theory. Discriminant analyses showed that on the basis of the $\mathrm{CO}$ variables alone, the subjects were classified correctly as patients or healthy in $77 \%$ to $86.3 \%$ of the cases, which indicates an improvement of $27 \%$ to $36.3 \%$ over the $50 \%$ of correct classification expected by chance. The best predictors of the belief types were beliefs about self and general beliefs, and of the factors the first factor (attaining peace and quiet in one's environment by self-regulation), the 
fourth factor (toughness in regard to oneself) and the sixth factor 6 (controlling others). Since the scores of the CO variables do not depend on demographic and medical characteristics, such as disease duration, disease site and stages, quality of life and age, the observed differences in the $\mathrm{CO}$ variables between patients and healthy controls may be considered as characterizing the tested groups of participants per se.

The described study was the first to show that there exists a set of psychological variables, defined on the basis of the CO theory, which characterize colon cancer patients and differentiate between them and healthy controls. These findings support the hypothesis that there is a set of comprehensive, diseaserelevant, reliable, specific psychological variables that may be considered as potential risk factors for colon cancer.

The findings were confirmed in a further study which showed that the CO questionnaire of colorectal cancer differentiated significantly not only between colorectal cancer patients and healthy controls but also between these two groups and a group of patients with Crohn's disease which is a disease with a potential for malignancy (Kreitler, Kreitler, Len et al., 2008). As expected, the scores of the latter patients were midway between those of the colorectal cancer patients and the healthy controls. The prediction of group membership by discriminant analysis was highly significant. In addition, the study identified the thematic structure of the CO questionnaire of colorectal cancer. The tendencies for compulsiveness, control of oneself and especially of anger, self effacement, pleasing others, self assertion, distancing oneself from others, keeping regulations, and performing to perfection all ones obligations formed the following three major foci: perfect duty performance, and two contradictory pairs: self effacement versus self assertion, and closeness to others versus distancing from others. The clusters and the contrasts constitute potentially sources of tension.

\section{The Present Study}

\section{Objectives}

The purpose of the present study was to examine in depth the claim of the specificity of the $\mathrm{CO}$ of colorectal cancer. As noted above, specificity is a major characteristic required of COdefined risk factors for a disease. Up to now the only basis for the claim of specificity of this $\mathrm{CO}$ is the method whereby the cognitive contents constituting it have been derived. In line with this method, the cognitive contents defining the themes of the CO questionnaire are based on interviewing according to a standard procedure individuals diagnosed with colorectal cancer and individuals without this disease. The specificity claim is further enhanced by the evidence, that the CO questionnaire of colorectal cancer differentiated significantly between patients with colorectal cancer and healthy controls, as well as patients with Crohn's disease, who merely have a tendency for malignancy. However, the procedure and the findings do not exclude the possibility that the $\mathrm{CO}$ questionnaire of colorectal cancer applies also to other types of cancer and differentiate between them and individuals without cancer. If that were the case, the $\mathrm{CO}$ questionnaire of colorectal cancer should be considered perhaps as the CO questionnaire of cancer in general. In view of this possibility, the purpose of the present study was to test the specificity of the CO questionnaire of colorectal cancer by applying it to two types of cancer other than colorectal cancer: prostate cancer and breast cancer. Because of the involvement of gender in the case of prostate and breast cancers, the groups of colorectal cancer patients and healthy controls used for comparison consisted also of one or the other gender. In this manner the specificity claim could be put to the test in a broader range of cancer diagnoses. Considering the specificity claim grounded in the $\mathrm{CO}$ theory, the hypotheses were that the $\mathrm{CO}$ questionnaire of colorectal cancer would differentiate between colorectal cancer patients, on the one hand, and prostate cancer patients or breast cancer patients as well as healthy controls, on the other hand. Further, the CO questionnaire of colorectal cancer would not differentiate significantly between prostate cancer patients and healthy controls or breast cancer patients and healthy controls. The rationale for these hypotheses is that the CO questionnaire of colorectal cancer is a tool specifically targeting the cognitive orientation of colorectal cancer.

\section{Method}

\section{Participants}

The participants in the study were 230 colorectal cancer patients (101 men and 129 women), whose mean age was 61.5 yrs, disease duration .5 to 7.3 yrs, with different diagnoses (47\% cancer of the rectum, $53 \%$ colon cancer), and in different disease stages (I 13.04\%, II 38.7\%, III 30\%, IV 18.26\%). The healthy controls included 165 individuals with no diagnosed diseases. They included 55 men and 110 women. The controls were matched to the patients in age and years of education. They were recruited in offices of the hospital where the study was conducted and in the university. Both of these groups included subjects who have participated in previous studies (Figer, Kreitler, \& Chaitchik, 2002; Kreitler et al., 2008). Two additional groups participated in the study: 61 male patients with prostate cancer and 53 female patients with breast cancer. Each group included patients of the four stages of disease. The prostate cancer patients and breast cancer patients were matched to the colorectal cancer patients and healthy controls in age and years of education. None of the participants in the three cancer groups had co-morbidity or psychiatric disorders.

\section{Tools}

All participants were administered the CO questionnaire of colorectal cancer, used in the previous studies (Figer, Kreitler, \& Chaitchik, 2002; Kreitler et al., 2008). The questionnaire included four parts administered together, referring to beliefs about self, general beliefs, beliefs about norms and beliefs about goals. In each part there were statements (a total of 181) referring to 44 themes, to which the subject was requested to respond by selecting one of the four response alternatives (e.g., "Very true", "True”, "Not true”, etc.). The questionnaire was presented without any special introduction so that the respondents did not know that it referred to colorectal cancer.

\section{Procedure}

The patient participants responded to the $\mathrm{CO}$ questionnaire when they visited the hospital for treatment or follow-up, and the healthy controls responded in their working places.

\section{Results}

The major variables used in the different analyses were the mean scores of the four types of beliefs.

Table 1 shows the results of mean comparisons between the 
Table 1.

Means and Sds and comparison of the scores of colorectal cancer patients and healthy controls in the four types of beliefs of the CO theory.

\begin{tabular}{clclc}
\hline Belief Type & \multicolumn{2}{c}{$\begin{array}{c}\text { Colorectal Cancer } \\
\text { Patient }(\mathrm{N}=230)\end{array}$} & \multicolumn{2}{c}{$\begin{array}{c}\text { Healthy Controls } \\
(\mathrm{N}=165)\end{array}$} \\
\hline & Mean & Sd & Mean & $\mathrm{Sd}$ \\
Beliefs about self & 2.79 & .34 & $2.52^{* * * *}$ & .26 \\
Beliefs about norms & 2.55 & .39 & $2.28^{* * *}$ & .31 \\
General beliefs & 2.69 & .35 & $2.38^{* * *}$ & .27 \\
Beliefs about goals & 2.75 & .36 & $2.49^{* * *}$ & .29 \\
\hline
\end{tabular}

Note. ${ }^{* * *}$ The mean differences in the four belief types between colorectal cancer patients and healthy controls are significant, $p<.001$.

group of colorectal cancer patients and the healthy controls, without differentiating between men and women. This table was designed to examine the validity of the CO questionnaire of colorectal cancer by test anew for differentiating between colorectal cancer patients and healthy controls. The results show that in all four mean scores of the four belief types the differences between colorectal cancer patients and the healthy controls were highly significant, with the patients scoring higher, as expected in line with the CO theory.

Table 2 presents the results of comparing the mean scores of the belief types of men and women in the sample of colorectal cancer patients and the healthy controls. The purpose was to examine to what extent the separate samples of men and women are sufficiently similar so that they can be used in further comparisons with patients presenting other kinds of cancer diagnoses. The comparisons show that men and women both in the sample of colorectal cancer patients and the healthy controls differ significantly only in the mean scores of beliefs about norms. In both cases men score higher than women. The fact that the gender difference appears in both samples in regard to the same variable and has the same directionality reduces its probable impact on further analyses with these variables.

Tables $\mathbf{3}$ and $\mathbf{4}$ present the results of the analyses that refer to the hypotheses of the study. Table 3 presents the results of comparing the male samples of colorectal cancer patients, prostate cancer patients and healthy controls. It shows that in regard to all four types of beliefs the overall mean differences are significant, and that the colorectal cancer patients differ from both the prostate cancer patients and the healthy controls, but the prostate cancer patients do not differ significantly from the healthy controls. These results conform fully to those hypothesized and expected.

Table 4 presents the results of comparing the female samples of colorectal cancer patients, breast cancer patients and healthy controls. It shows that in regard to all four types of beliefs the overall mean differences are significant, and that the colorectal cancer patients differ from both the breast cancer patients and the healthy controls, but the breast cancer patients do not differ significantly from the healthy controls. These results conform fully to those hypothesized and expected.

Another analysis was performed for comparing the mean scores of the prostate cancer patients with those of the breast cancer patients (see column 2 in Table 3 and column 2 in Table 4). The results showed that only in one belief type the mean scores of these two groups differed significantly: in norm beliefs the mean score of the prostate cancer patients was higher
Table 2.

Comparing the means and Sd of the scores of men and women in the four belief types in colorectal cancer patients and healthy controls.

\begin{tabular}{lcccc}
\hline Belief Type & \multicolumn{2}{c}{ Colorectal Cancer Patients } & \multicolumn{2}{c}{ Healthy Controls } \\
\cline { 2 - 5 } & $\begin{array}{c}\text { Men } \\
(\mathrm{N}=101)\end{array}$ & $\begin{array}{c}\text { Women } \\
(\mathrm{N}=129)\end{array}$ & $\begin{array}{c}\text { Men } \\
(\mathrm{N}=55)\end{array}$ & $\begin{array}{c}\text { Women } \\
(\mathrm{N}=110)\end{array}$ \\
\hline $\begin{array}{l}\text { Beliefs } \\
\text { about self }\end{array}$ & $2.80[.34]$ & $2.78[.33]$ & $2.54[.22]$ & $2.50[.28]$ \\
$\begin{array}{l}\text { Beliefs } \\
\text { about norms }\end{array}$ & $2.64[.41]$ & $2.47[.36]^{\mathrm{a}}$ & $2.36[.27]$ & $2.24[.32]^{\mathrm{b}}$ \\
$\begin{array}{l}\text { General } \\
\text { beliefs }\end{array}$ & $2.73[.36]$ & $2.65[.34]$ & $2.42[.23]$ & $2.36[.29]$ \\
$\begin{array}{l}\text { Beliefs } \\
\text { about goals }\end{array}$ & $2.79[.40]$ & $2.72[.33]$ & $2.52[.27]$ & $2.48[.30]$ \\
\hline
\end{tabular}

Note. In columns 2-4 the number without brackets represents the mean score and the number in brackets represents the $\mathrm{Sd}$. ${ }^{\text {a }}$ The difference between the mean scores of men and women is significant $p<.001$. ${ }^{\mathrm{b}}$ The difference between the mean scores of men and women is significant $p<.05$.

Table 3.

Comparing the means of the four belief types in the three samples of men: colorectal cancer patients, patients with prostate cancer, and healthy controls.

\begin{tabular}{lcccc}
\hline Belief Type & $\begin{array}{c}\text { Colorectal } \\
\text { Cancer } \\
(\mathrm{N}=101)\end{array}$ & $\begin{array}{c}\text { Prostate } \\
\text { Cancer } \\
(\mathrm{N}=61)\end{array}$ & $\begin{array}{c}\text { Healthy } \\
\text { Controls } \\
(\mathrm{N}=55)\end{array}$ & $\begin{array}{c}\mathrm{F} \\
\mathrm{DF}=2 / 214\end{array}$ \\
\hline $\begin{array}{l}\text { Beliefs } \\
\text { about self }\end{array}$ & $2.80[.34]$ & $2.58[.21]$ & $2.54[.22]$ & $14.12^{* * *}$ \\
$\begin{array}{l}\text { Beliefs } \\
\text { about norms }\end{array}$ & $2.64[.41]$ & $2.40[.30]$ & $2.36[.27]$ & $29.64^{* * *}$ \\
$\begin{array}{l}\text { General beliefs } \\
\begin{array}{l}\text { Beliefs } \\
\text { about goals }\end{array}\end{array}$ & $2.73[.36]$ & $2.43[.25]$ & $2.42[.23]$ & $22.17^{* * *}$ \\
\hline
\end{tabular}

Note. In columns 2-4 the number without brackets represents the mean score and the number in brackets represents the Sd. ${ }^{* * *} p<.001$. Comparisons of pairs of means by the Scheffe post hoc method yielded significant results for the means of colorectal cancer versus prostate cancer, and for colorectal cancer versus healthy controls for each of the four belief types. In no case was the difference between the means of prostate cancer and healthy controls significant.

Table 4.

Comparing the means of the four belief types in the three samples of women: colorectal cancer patients, patients with breast cancer, and healthy controls.

\begin{tabular}{lcccc}
\hline Belief Type & $\begin{array}{c}\text { Colorectal } \\
\text { Cancer } \\
(\mathrm{N}=129)\end{array}$ & $\begin{array}{c}\text { Breast } \\
\text { Cancer } \\
(\mathrm{N}=53)\end{array}$ & $\begin{array}{c}\text { Healthy } \\
\text { Controls } \\
(\mathrm{N}=110)\end{array}$ & $\begin{array}{c}\mathrm{F} \\
\mathrm{DF}=2 / 289\end{array}$ \\
\hline $\begin{array}{l}\text { Beliefs } \\
\text { about self }\end{array}$ & $2.78[.33]$ & $2.52[.21]$ & $2.50[.28]$ & $20.71^{* * *}$ \\
$\begin{array}{l}\text { Beliefs } \\
\text { about norms }\end{array}$ & $2.47[.36]$ & $2.28[.30]$ & $2.24[.32]$ & $13.83^{* * *}$ \\
$\begin{array}{l}\text { General } \\
\text { beliefs }\end{array}$ & $2.65[.34]$ & $2.41[.31]$ & $2.36[.29]$ & $14.75^{* * *}$ \\
$\begin{array}{l}\text { Beliefs } \\
\text { about goals }\end{array}$ & $2.72[.33]$ & $2.50[.32]$ & $2.48[.30]$ & $10.87^{* * *}$ \\
\hline
\end{tabular}

Note. In columns 2-4 the number without brackets represents the mean score and the number in brackets represents the Sd. ${ }^{* * *} p<.001$. Comparisons of pairs of means by the Scheffe post hoc method yielded significant results for the means of colorectal cancer versus breast cancer, and for colorectal cancer versus healthy controls for each of the four belief types. In no case was the difference between the means of breast cancer and healthy controls significant. 
than that of the breast cancer patients $(p<.01)$. Notably the mean score of norm beliefs was higher for mean than for women also in the sample of colorectal cancer patients and in the sample of healthy controls.

\section{Discussion}

The results of the presented study show that both hypotheses were confirmed: the $\mathrm{CO}$ questionnaire of colorectal cancer differentiated the male colorectal cancer patients from the healthy controls and prostate cancer patients, but did not differentiate the prostate cancer patients from the healthy controls. The same was true of breast cancer patients: the $\mathrm{CO}$ questionnaire of colorectal cancer differentiated the female colorectal cancer patients from the healthy controls and breast cancer patients, but did not differentiate the breast cancer patients from the healthy controls. Further, it did not differentiate between the prostate cancer patients and the breast cancer patients except in regard to beliefs about norms. Hence, it may be concluded that the $\mathrm{CO}$ questionnaire of colorectal cancer is specifically targeted on colorectal cancer and differentiates patients with this diagnosis from healthy controls and from patients with other types of cancer but does not differentiate the other types of cancer from healthy controls.

The findings of the study provide a sturdy proof of the specificity of the $\mathrm{CO}$ of disease particularly in regard to colorectal cancer. The proof is enhanced especially through the finding that it refers to two types of cancer-prostate cancer and breast cancer.

A notable result is the recurrent finding that men score higher on norm beliefs in the samples of colorectal cancer, healthy controls and in comparing prostate cancer patients with breast cancer. In the sample of colorectal cancer patients the finding is in accord with the evidence that in men colorectal cancer tends to be a more severe disease than in women (Gao et al., 2008; Kotake et al., 2003). However, this interpretation does not hold for the finding in the other samples. Further research is needed to clarify the reasons for this finding.

\section{Conclusion}

The major thrust of the results is that they contribute to strengthening the claim that psychological risk factors defined in terms of the CO theory are disease specific. The implications of this result are important both in regard to the better understanding the disease itself and in regard to enhancing the role of psychological risk factors in the domain of medicine.

Concerning the disease, it seems justified to conclude that there exists a profile of psychological tendencies characteristic of colorectal cancer. Its main characteristics are that it is a profile and not one or another tendency, and that the tendencies constitute together a matrix of dynamic interactions manifesting how the individuals experience reality, how they handle themselves and how they interact with others. The major focus of their cognitive orientation concerns striving to be perfect in performing all one's duties, commitments and direct as well as indirect expectations of oneself. The further focus concerns the relation to oneself as defined in terms of the polarity of self assertion or self effacement. The relation to others is defined in terms of the polarity of yearning for closeness and pleasing others contrasted with the tendency to distancing oneself from others. The polarities denote the constant potentiality for con- flict if both contrasting tendencies are activated at the same time. But if however, only one tendency is activated, the individual may feel frustrated at not having expressed oneself fully or completely. The potential conflicts form major sources of tension.

In view of the findings of the present study it seems appropriate to suggest that the identified personality tendencies could be considered as likely candidates for psychological risk factors for colorectal cancer. The justification for this suggestion rests on the evidence provided by the present study about the specificity of the identified psychological tendencies as well as on previous findings, primarily those indicating that they do not vary with various demographic variables, such as age, country of origin or marital status; that they are independent of various medical variables, mainly disease stage, being in treatment or in remission, and mainly disease duration, which could potentially change the individual's behavior and emotional state; and they are readily amenable to assessment by a reliable and valid tool. The dictionary of cancer terms prepared by the National Cancer Institute (NCI) defines risk factors as something that may increase the chance of getting a disease, for example, risk factors for cancer include age, a family history of certain cancers, use of tobacco products, certain eating habits, obesity, lack of exercise, exposure to radiation or other cancer-causing agents, and certain genetic changes. The identified psychological tendencies grounded in the CO theory seem to fit in very well within this framework of risk factors.

\section{REFERENCES}

Amelang, M. (1997). Using personality variables to predict cancer and heart disease. European Journal of Personality, 11, 319-342. http://dx.doi.org/10.1002/(SICI)1099-0984(199712)11:5<319::AIDPER304>3.0.CO;2-D

Drechsler, I., Brunner, D., \& Kreitler, S. (1987). Cognitive antecedents of coronary heart disease. Social Science and Medicine, 24, 581-588. http://dx.doi.org/10.1016/0277-9536(87)90062-1

Denollet, J. (1998). Personality and risk of cancer in men with coronary heart disease. Psychological Medicine, 28, 991-995. http://dx.doi.org/10.1017/S0033291797006442

Figer, A., Kreitler, S., Kreitler, M. M. et al. (2002). Personality dispositions of colon cancer patients. Gastrointestinal Oncology, 4, 81-92. http://dx.doi.org/10.1080/1475956021000015095

Fox, B. (1998) Psychosocial factors in cancer incidence and prognosis. In J. Holland (Ed.), Psycho-oncology (pp. 110-124). New York: Oxford University Press.

Gao, R. N., Neutel, C. I., \& Wai, E. (2008). Gender differences in colorectal cancer incidence, mortality, hospitalizations and surgical procedures in Canada. Journal of Public Health, 30, 194-201. http://dx.doi.org/10.1093/pubmed/fdn019

Goodkin, K., Antoni, M. H., Sevin, B., et al. (1993). A partially testable predictive model of psychosocial factors in the etiology of cervical cancer. I. Biological, psychological and social aspects. Psychooncology, 2, 79-98. http://dx.doi.org/10.1002/pon.2960020203

Kotake, K., Honjo, S., Sugihara, K. et al. (2003). Changes in colorectal cancer during a 20-year period: An extended report from the multi-institutional registry of large bowel cancer, Japan. Diseases of the Colon \& Rectum, 46, S32-S43.

Kreitler, H., \& Kreitler, S. (1976). Cognitive orientation and behavior. New York: Springer Publishing.

Kreitler, H., \& Kreitler, S. (1982). The theory of cognitive orientation: Widening the scope of behavior prediction. In B. Maher, \& W. B. Maher (Eds.), Progress in experimental personality research (Vol. 11, pp. 101-169). New York: Academic Press.

Kreitler, S. (2003). Psycho-oncology. In L. M. Cohen, D. E. McChargue, \& F. L. Collins Jr. (Eds.), The health psychology handbook (pp. 
325-358). Thousand Oaks: Sage Publications.

Kreitler, S. (2004). The cognitive guidance of behavior. In J. T. Jost, M. R. Banaji, \& D. A. Prentice (Eds.), Perspectivism in social psychology: The Yin and Yang of scientific progress (pp. 113-126). Washington DC: American Psychological Association.

Kreitler, S., \& Kreitler, H. (1991a). Cognitive orientation and physical disease or health. European Journal of Personality, 5, 109-129. http://dx.doi.org/10.1002/per.2410050205

Kreitler, S., \& Kreitler, H. (1991b). The psychological profile of the health-oriented individual. European Journal of Personality, 5, 3560. http://dx.doi.org/10.1002/per.2410050104

Kreitler, S., \& Kreitler, H. (1998). Cognitive orientation and disease in cancer patients. Psychooncology, 1, 174.

Kreitler, S., Kreitler, H., \& Chaitchik, S. (1993). Repressiveness: Cause or result of cancer? Psychooncology, 2, 43-54. http://dx.doi.org/10.1002/pon.2960020107

Kreitler, S., Levavi, H., \& Bornstein, G. (1996). Personality factors and cervical premalignancy. Personality and Individual Differences, 21, 883-890. http://dx.doi.org/10.1016/S0191-8869(96)00136-5

Kreitler, S., Kreitler, M. M., Len, A., Alkalay, Y., \& Barak, F. (2008). Psychological risk factors for colorectal cancer? Psycho-Oncologie, 2, 131-145. http://dx.doi.org/10.1007/s11839-008-0094-9
Lilja, A. O., Smith, G., Malmstroem, P. et al. (1998). Psychological profile related to malignant tumors of different histopathology. Psychooncology, 7, 376-386.

http://dx.doi.org/10.1002/(SICI)1099-1611(1998090)7:5<376::AIDPON311>3.0.CO;2-Z

Nurymberg, K., Kreitler, S., \& Weissler, K. (1996). The cognitive orientation of compliance in short- and long-term type 2 diabetic patients. Patient Education and Counseling, 29, 25-39. http://dx.doi.org/10.1016/0738-3991(96)00931-7

Sanderman, R., \& Ranchor, A. V. (1997). The predictor status of personality variables: Etiological significance and their role in the course of disease. European Journal of Personality, 11, 359-382. http://dx.doi.org/10.1002/(SICI)1099-0984(199712)11:5<359::AIDPER307>3.0.CO;2-0

Servaes, P., Vingerhoets, A. J. J. M, Vreugdenhil, G. et al. (1999). Inhibition of emotional expression in breast cancer patients. Behavioral Medicine, 25, 23-27. http://dx.doi.org/10.1080/08964289909596735

Temoshok, L., Heller, B. W., Sagebiel, R. W. et al. (1985). The relationship of psychosocial factors to prognostic indicators in cutaneous malignant melanoma. Journal of Psychosomatic Research, 29, 139153. http://dx.doi.org/10.1016/0022-3999(85)90035-2 